\title{
Assessment of the effect of intraarticular injection of autologous adipose-derived mesenchymal stem cells in osteoarthritic dogs using a double blinded force platform analysis
}

Jose M Vilar ${ }^{1 *}$, Miguel Batista', Manuel Morales ${ }^{1}$, Angelo Santana ${ }^{1}$, Belén Cuervo ${ }^{2,3,4,5}$, Mónica Rubio 2,3,4,5, Ramón Cugat ${ }^{3,4,6}$, Joaquín Sopena ${ }^{2,3,4,5}$ and Jose M Carrillo $2,3,4,5$

\begin{abstract}
Background: Regenerative medicine using Mesenchymal Stem Cells (MSC) alone or combined with Plasma Rich in Growth Factors (PRGF) is a rapidly growing area of clinical research and is currently also being used to treat osteoarthritis (OA). Force platform analysis has been consistently used to verify and quantify the efficacy of different therapeutic strategies for the treatment of OA in dogs including MSC associated to PRGF, but never with AD-MSC alone.

The aim of this study was to use a force platform to measure the efficacy of intraarticular ADMSC administration for limb function improvement in dogs with severe OA.

Results: Ten lame dogs with severe hip OA and a control group of 5 sound dogs were used for this study. Results were statistically analyzed to detect a significant increase in peak vertical force (PVF) and vertical impulse (VI) in treated dogs. Mean values of PVF and VI were significantly improved within the first three months post-treatment in the OA group, increasing $9 \%$ and $2.5 \%$ body weight, respectively, at day 30 . After this, the effect seems to decrease reaching initial values.
\end{abstract}

Conclusion: Intraarticular ADMSC therapy objectively improved limb function in dogs with hip OA. The duration of maximal effect was less than 3 months.

Keywords: Osteoarthrosis, Hip, Adipose-derived mesenchymal stem cells, MSC, Force platform

\section{Background}

Osteoarthritis $(\mathrm{OA})$ is a common degenerative disease in veterinary medicine that affects various tissues surrounding joints such as articular cartilage, subchondral bone, synovial membrane, and ligaments, although cartilage is the main tissue afflicted by OA [1-3]. However, restoration of the diseased articular cartilage in patients with $\mathrm{OA}$ is still a challenge for researchers and clinicians. Currently, several therapeutic regenerative strategies have investigated whether autologous mesenchymal stem

\footnotetext{
* Correspondence: jvilar@dpat.ulpgc.es

'Department of Animal Pathology, Faculty of Veterinary Medicine, Universidad de Las Palmas de Gran Canaria, Trasmontaña S/N, Arucas, 35413 Las Palmas, Spain

Full list of author information is available at the end of the article
}

cells (MSCs) have significant effects on regeneration and/or maintenance of articular cartilage in OA [4-6].

Autologous MSC therapy is based on the isolation of these cells from tissues such as fat or bone marrow [7] and then after culture expansion, they are administered back to the patient [8] on account of the demonstrated affinity that MSCs have for damaged joint tissue, such as cruciate ligaments, menisci, and cartilage [9]. In veterinary medicine, previous studies evaluating autologous ADMSC therapy showed clinical improvement in horses and dogs with orthopedic conditions [10-14]. Recent investigations have shown that growth factors contained in platelet-rich plasma (PRGF) act as vehicles that could act as potentiators or even extend the effect of MSCs $[6,15,16]$. This may be explained by the antiinflammatory effect of 
PRGF, which could help the MSCs differentiate in a more favorable environment [3]. At this point, knowing the onset and duration of action MSCs have in canine OA should be highly interesting, as well as further understanding of their efficacy. If previous subjective studies seem to show certain effects, our research hypothesis should be that this effect could be detected and quantified by kinetik devices such as force platforms. The aim of this study was to use force platform kinetic analysis to demonstrate that the effect of a single intraarticular injection of ADMSCs alone is more limited with respect to time, compared with ADMSCs + PRGF in 10 dogs with hip OA. The obtained results were compared with other medical strategies in canine OA and the advantages and disadvantages discussed.

\section{Results}

The body weight of enrolled dogs ranged from 44 to $56 \mathrm{~kg}$ (mean $\pm \mathrm{SD}=50.51 \pm 6.76 \mathrm{~kg}$ ), and ages were 4 to 8 years $(5.2 \pm 1.7$ years). The mean $( \pm \mathrm{SD})$ value for walking velocity of both sound (control) and diseased groups of dogs was $1.6 \pm 0.5 \mathrm{~m} / \mathrm{s}$. No significant difference in walking velocity existed between $\operatorname{dogs}(P=0.06)$. PVF and VI mean values are summarized in Table 1.

\section{Analysis of PVF}

More-lame limbs analysis showed that differences in \% PVF between D0 and D30 were significant ( $\mathrm{p}$-value < 0.001 ). Between the other periods, differences were of no significance ( $p$-value $>0.93$ ).

Compared with the control group, \% PVF at D0, D90 and D180 is significantly less ( $p$-value $<0.001$ ). In comparison, at D30 difference was non significant ( $\mathrm{p}$-value $=0.666$ ).

Less-lame limbs analysis showed non significant differences at all study periods ( $\mathrm{p}$-value $<0.588$ ).

Compared with control group, \% PVF at D30, D90 and D180 is significantly greater ( $p$-value $<0.001$ ). At D0 this difference was non significant $(\mathrm{p}$-value $=0.114)$ (Figure 1$)$.

Table 1 Mean and standard deviation of PVF and VI $(n=9)$ in \% dog weight (N/N and N.s/N, respectively) applied on the diseased leg

\begin{tabular}{ccccc}
\hline Day & $\mathbf{0}$ & $\mathbf{3 0}$ & $\mathbf{9 0}$ & $\mathbf{1 8 0}$ \\
\hline PVF ML & $40.14 \pm 2.13$ & $49.22 \pm 0.961$ & $41.62 \pm 1.32$ & $39.73 \pm 0.96$ \\
PVF LL & $51.77 \pm 0.79$ & $53.69 \pm 0.38$ & $53.25 \pm 0.64$ & $51.91 \pm 1.22$ \\
PVF S & $47.40 \pm 1.43$ & $47.74 \pm 1.34$ & $47.95 \pm 1.35$ & $47.94 \pm 1.65$ \\
VI ML & $12.19 \pm 0.60$ & $14.76 \pm 0.29$ & $12.48 \pm 0.4$ & $11.95 \pm 0.29$ \\
VI LL & $15.65 \pm 0.31$ & $16.16 \pm 0.1$ & $15.98 \pm 0.2$ & $15.65 \pm 0.38$ \\
VI S & $14.51 \pm 0.47$ & $14.62 \pm 0.41$ & $14.67 \pm 0.42$ & $14.67 \pm 0.51$ \\
\hline
\end{tabular}

PVF ML: peak vertical force in the more-lame limbs. PVF LL: peak vertical force in the less-lame limbs. VI ML: vertical impulse in the more-lame limbs VI LL: vertical impulse in the less-lame limbs. PVF S: peak vertical force in the control group. VI S:vertical impulse in the control group.

Data are shown for each day of observation.

\section{VI analysis}

More-lame limbs analysis showed that differences in \% VI between D0 and D30 were significant (p-value $<$ $0.001)$. With the other periods, differences were not significant ( $\mathrm{p}$-value $>0.99$ ).

Compared with the control group, \% VI at D0, D90 and $\mathrm{D} 180$ is significantly less ( $\mathrm{p}-\mathrm{val}<0.001)$. In comparison, at D30 difference became non significant ( $p$-value $>0.44$.

Less-lame limbs analysis showed no significant differences at any control period ( $\mathrm{p}$ value $=0.579$ ).

Compared with the control group, significant differences at D30 and D90 were found (p-values < 0.001) (Figure 2).

\section{Association between more and less-lame limbs}

The fitted linear mixed model shows a negative association between \% PVF in less-lame limb and more-lame $\operatorname{limb}\left(\beta_{1}=0\right.$, $\mathrm{p}$-value $\left.=0.015\right)$. In \% VI the same was found $\left(\beta_{1}=0, \mathrm{p}\right.$-val $\left.=0.34\right)$.

The validity of the model fit was assessed by testing normality and homoscedasticity of the residuals. Both assumptions could be accepted: the Shapiro-Wilk test for normality and Levene's test for homoscedasticity were not significant $(\mathrm{P}=0.79$ and $\mathrm{P}=0.89$, respectively).

\section{Discussion}

The aim of the current study was to test the effectiveness of ADMSCs in lame OA dogs using a force platform. The ground reaction forces-related aspects of the gait, such as the PVF and VI, which represent maximal weight bearing and distribution of forces through time, respectively. Allowing for the objective measurement of the clinical impact of ADMSC treatment on the function of the limb during the stance phase of walking. Force platform analysis could be complemented with kinematic studies since three-dimensional kinematic alterations in hip dysplasia have been well described $[17,18]$.

The lack of a direct relationship between radiographic evidence of $\mathrm{OA}$ and force platform findings is well known; in the current study, diseased dogs were selected both on the basis of the presence or absence of radiographic signs of severe OA (D-E degrees of hip dysplasia) and for clear lameness determined by platform gait analysis objectively [19].

Some authors $[20,21]$ reported that force platform gait analysis at trot was much more sensitive than at walk for low-grade hind limb lameness, but not for severe lameness. Based in previous experience [22], in the OA dogs group lameness was evident by direct observation, even at walk.

Although each dog had bilateral lameness, the authors believed that it would only be possible to obtain confident data from the more-lame limbs (lesser PVF), in order to avoid a possible bias caused by inconsistent weight redistribution to the less affected contra-lateral 


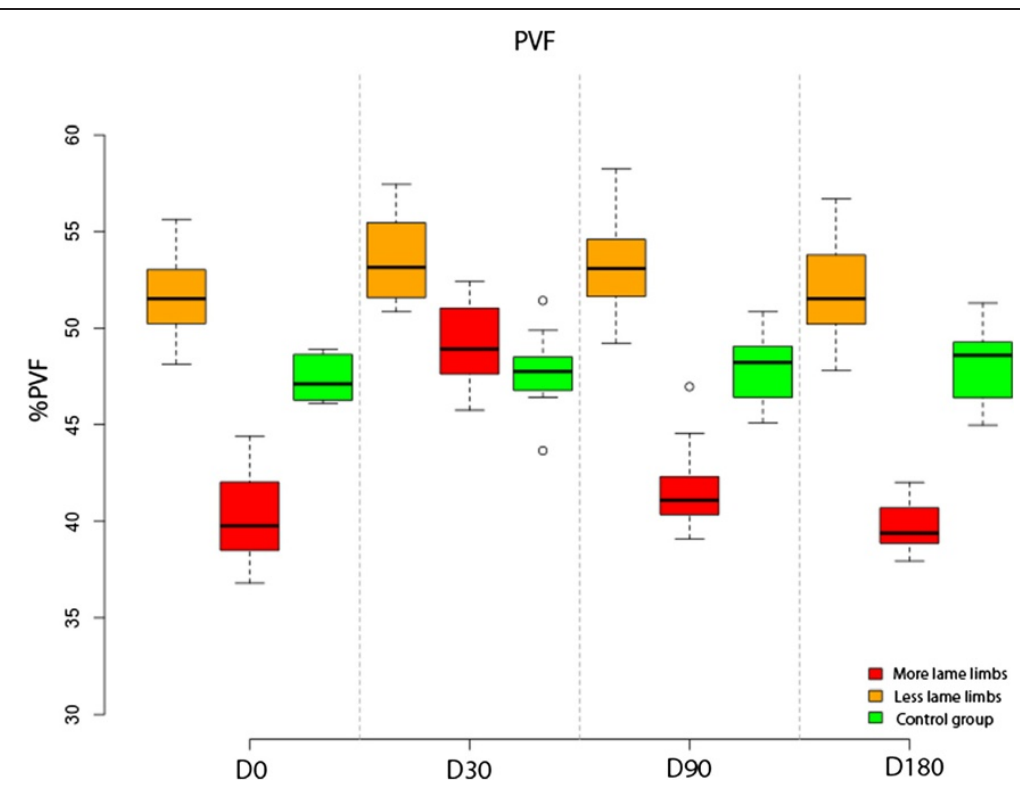

Figure 1 Evolution of PVF in lame group dogs after treatment at the 6-month follow-up period.

hind limb. In fact, mean values showed how less-lame limbs seemed to perform better than limbs from the control group over the whole study period.

A substantial improvement was observed both in PVF and VI values, but only in the first month post inoculation of ADMSCs; afterwards the animals seemed to worsen returning to the pretreatment condition. Although some authors [6,23-25] found independent evolution of both PVF and VI values, in this study it was showed how these two parameters progressed consistently during the different study periods; the authors believe that this occurred due to the limited effect of the treatment in terms of time; after D30, beyond this point, animals clearly returned to the initial state.

Selection of a control group is determinant to test the efficacy of a treatment for lameness; in fact, when a treated group could improve its lameness, a lame nontreated or placebo control group could worsen, making these animals unable to provide fixed reference data [26]. In accordance with this, the experimental study

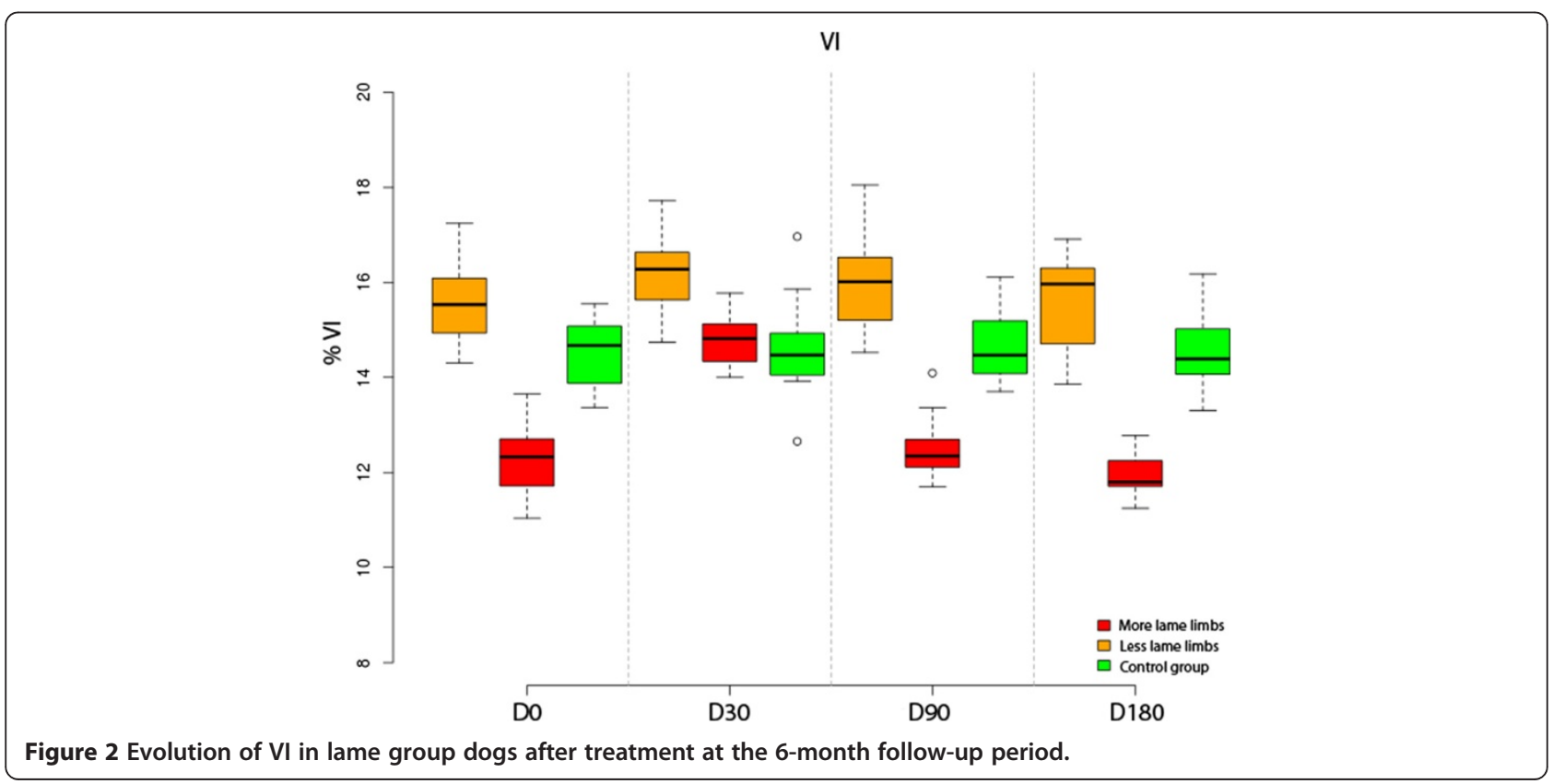


developed here used a control group of sound dogs that could provide fixed reference data.

Various adipose tissue donor sites have been reported in revised literature: retroperitoneal adipose tissue [27], lateral thoracic area [28], gluteous fat [29] or inguinal region $[8,30]$. The authors preferred this location to others for its easier access, abundant quantities of fat, absence of surgical complications and production of a non-visible scar.

With regards to the role that other adjuvants associated to ADMSC could play increasing the effect, some results published in 2003 showed that the use of MSCs deposited in a fibrin matrix would be useful [31]. More recently, another study [6] objectively demonstrated how the effect of the association ADMSC + PRGF-Endoret was prolonged beyond six months; however the current study showed evidence that ADMSCs alone have a significant but short effect in terms of time. Based on these results, it is likely that modulation of the matrix or cells will need to be accomplished to observe long-term benefit of MSCs for cartilage repair [3]. Not only could adjuvants play a role in the duration of effect of MSCs therapy; joint idiosyncrasy, and more specifically primary pathologies that cause joint instability such as hip dysplasia or cranial cruciate ligament rupture, they could also noticeably shorten the effect because of the constant reactivation of the associated OA. Presence of sideeffects in MSC therapy has also been recently investigated: comparing intra-articular injections of autologous, allogeneic and xenogenic MSCs in horses, only a moderate acute inflammatory response was developed, less evident in autologous cells [5]. In this study, only one dog experimented a transitory worsening after injection. This fact could probably be attributable to incorrect technique in the administration of the cells, because the researcher had to perform various attempts to reach the articular space.

This study objectively demonstrated that a single intraarticular administration of ADMSCs alone decreases pain and lameness in dogs with OA during a period less than three months, at which point PVF and VI values returned to being similar to the pre-treatment status. These results differ with those previously published [6] where improvement was still present after six months of treatment with MSCs associated to PRGF Endoret ${ }^{\circ}$. The identical study design suggests that PRGF strongly plays a potentiating role, potentiating the effect of MSC therapy, as shown by other authors [15,16]. In 2007 [13] a multicentre study with MSC alone showed subjective improvement during a 3-month period using different scoring systems, although the results from the current study were supported by objective kinetic data, the different study design (different breeds and conformations, use of a diseased control group) could explain these differences. On the other way, the authors are of the opinion that a follow up of six months could be considered as a standard for testing the evolution of medical or surgical treatments; in fact although the dogs in the current study seemed to improve during the first month after treatment, this effect was reverted before three months after treatment. This fact should induce researchers to objectively determine when a new cycle of treatment should be useful to stop a relapse [32], and clinicians to set out a therapeutic strategy that should be based in MSC associated to PRGF, since a much longer-lasting effect has been demonstrated [6,33].

Regarding statistical analysis, more complex models could have been considered but the authors chose this one because it offers an adequate compromise between complexity and ability to represent the relationships between the considered variables $[34,35]$.

\section{Conclusion}

The measurement of PVF and VI during a follow-up period of six months demonstrated quantitatively that the efficacy of ADMSc therapy alone is significant in terms of improvement of hip joint lameness due to OA, although this effect decreased progressively between D30 and D90.

\section{Methods}

The research protocol was revised and authorized by the Ethics Committee of Animal Welfare (CEBA) at the University of Las Palmas de Gran Canaria (Spain) with reference code: 001/2010 CEBAULPGC.

\section{Animals}

Nine adult client-owned Canarian Presa dogs (5 males, 4 females) with lameness and pain attributed to OA associated with hip dysplasia were included in the study (one of the ten initially selected was finally discarded because it was lost to follow up). The dogs were affected by chronic OA and had not received any kind of medication (e.g., non-steroidal anti-inflammatory drugs, analgesics), nutraceuticals (e.g., glucosamine or chondroitin, vitamin E, omega-3 fish oil), or adjunctive therapies (e.g., acupuncture) for at least 2 months. A control group consisted of 5 sound and healthy dogs of the same breed.

None of the dogs were forced to perform physical activity. Dog owners were informed and granted a signed consent for the whole procedure.

Ventrodorsal radiographs were performed under sedation with dexmedetomidine $0.05 \mathrm{mg}$ IV (dexdomitor, Esteve, Barcelona, Spain) and analgesia with butorfanol $0.05 \mathrm{mg} / \mathrm{kg}$ (torbugesic, Pfizer, Madrid, Spain). The obtained images confirmed the presence of OA compatible with $\mathrm{D}$ and $\mathrm{E}$ degrees of hip dysplasia as defined by the Fédération Cynologique Internationale (World Canine Organization).D- degree dysplasic dogs showed obvious 
deviation from the normal with evidence of a shallow acetabulum, flattened femoral head, poor joint congruency, and in some cases, subluxation with marked changes of the femoral head and neck. E-degree dysplasic dogs showed complete dislocation of the hip and severe flattening of the acetabulum and femoral head [36]. Additional radiographs of knee and elbow joints and lumbosacral region were taken after physical, orthopedic and neurologic examinations were performed to ensure that hip OA was the main reason for the observed clinical signs and that general health was otherwise normal.

\section{Extraction and culture of ADMSCs}

Stem cell extraction phase was performed under premedication with a combination of buprenorfine $0.01 \mathrm{mg} / \mathrm{kg}$ IM (buprex, RB Pharmaceuticals, Bogotá, Colombia) and acepromazine $0.05 \mathrm{mg} / \mathrm{kg}$ IM (equipromacina, Fatro ibérica, Barcelona, Spain); general anesthesia was induced with propofol $3 \mathrm{mg} / \mathrm{kg}$ (vetofol, Esteve, Barcelona, Spain) and maintained with sevofluorane (sevoflo, Abbott, Madrid, Spain). Patients were positioned in decubitus supinus. A biopsy of $20 \mathrm{~g}$ of subcutaneous fat tissue $\left(4-5 \mathrm{~cm}^{3}\right)$ was collected from the inguinal region through a small surgical incision, and $120 \mathrm{ml}$ of blood was isolated under aseptic conditions and processed with the DogStem ${ }^{\circ}$ kit according to manufacturer's instructions. The incision was sutured with a simple, interrupted pattern. Meloxicam $0.1 \mathrm{mg} / \mathrm{kg} /$ $24 \mathrm{~h}$ PO (metacam, Boehringer ingelheim, Barcelona, Spain) was administered during 3 days post-surgery.

Immediately after sample collection, fat biopsy and blood (in anti-coagulant container) were sent at $4{ }^{\circ} \mathrm{C}$ for cell isolation and amplification under current GMP conditions to the Fat-Stem Laboratory (Belgium). The fat was processed with colagenase and by centrifugation the cells were concentrated; the cells were cultured in a biorreactor with controlled temperature as well as $\mathrm{O}_{2}$ and $\mathrm{CO}_{2}$ concentration. Quality control was based in cell markers, sterility tests and viability counts. Two weeks after biopsy the Fat-Stem Laboratory returned the cultivated cells in two $2 \mathrm{ml}$ certified tubes containing 15 million adipose mesenchymal stem cells per tube.

\section{Inoculation of ADMSCs}

Once the ADMSCs were received they were infiltrated aseptically into the hip joints through conventional arthrocentesis sites. For this phase the dogs were previously sedated with the same protocol used to take the radiographs.

The needle was introduced just cranioproximal to the trochanter major, aimed slightly ventrally and caudally. The appearance of joint fluid confirmed proper needle placement [37]. Once the excessive synovial liquid was drained, the AMSCs were injected. Owners were advised to use meloxicam, if needed.

\section{Gait analysis}

Gait analysis was performed using a single platform mounted in the center of, and level with, a 7-m runway covered by a rubber mat. The mat weight was discarded setting to "0 force" with the tare button after the platform was covered. Dogs were leash guided at walk over the force platform by the same handler. Walk velocity was measured by use of a motion sensor (Pasco, California, USA) positioned $1 \mathrm{~m}$ from the platform. This device allowed the handler to ensure that animals walked homogeneously in a narrow interval of velocity $(1.6 \pm 0.5 \mathrm{~m} / \mathrm{s})$ and acceleration $\left(\leq \pm 0.5 \mathrm{~m} / \mathrm{s}^{2}\right)$.

Five valid trials, at a sampling frequency of $250 \mathrm{~Hz}$, were obtained for each dog by a blind researcher (JMV). A trial was considered valid when the limb fully contacted the force platform, and with the dog walking next to the handler without pulling on the leash. The trial was discarded if the dog was distracted during the measurement, if the limb struck the edge of the force plate, or if any portion of the contralateral paw hit the force plate. A member of the research team (BC) evaluated the trial to confirm which limb touched the center of the force platform.

The platform was interfaced with a dedicated computer using DataStudio (Pasco, California, USA), software specially designed for the acquisition, numerical conversion, and storage of data. A team member (JMV) recorded data from both affected limbs at day 0, 30, 90, and 180 post-treatment; the obtained PVF and VI values were normalized relative to body weight (\%) to characterize the possible improvement of lameness during treatment with MSCs.

\section{Statistical analysis}

Parameters in this model were estimated by using the package nlme in the R statistical software [38].

Data were analyzed by a different, blinded researcher (AS) who did not perform acquisition of data.

For the analysis of these data, a linear mixed effects model for a blocked design with repeated measures was considered $[34,35]$. The experimental factor (time) and the status (lame-sound) of the dog were considered as fixed effects factors, while the blocking factor (dog) was a random effects factor. Because the dogs represent a random sample of the population of interest, any interaction terms modeling differences between dogs in its response when changing from different observation periods will also be expressed as random effects. Thus, the model considered is of the form:

$$
y_{i j k l}=\beta_{i}+\gamma_{j}+(\beta \gamma)_{i j}+b_{j k_{j}}+b_{i j k_{j}}+\epsilon_{i j k_{j} l}
$$

with $i=0,1,3,6$ (months), $j=0$ (sound), 1 (lame), $k_{0}=1, \ldots, 8$, $k_{1}=1, \ldots, 5, l=1, \ldots, 5$. In this model, $\beta_{i}$ represents the effect 
of time, $\gamma_{j}$ the effect of the dog being sound or lame and $(\beta \gamma)_{\mathrm{ij}}$ the interaction between these factors. The term $b_{\mathrm{jk}}$ represents the random effects of the dogs, and the $b_{\mathrm{ijk}}$ represents the random interaction terms between dogs and time, being:

$$
b_{j k_{j}} \sim N\left(0, \sigma_{1}^{2}\right), b_{i j k_{j}} \sim N\left(0, \sigma_{i}^{2}\right), \epsilon_{i j k_{j} l} \sim N\left(0, \sigma^{2}\right)
$$

Significance of the differences in PVF and VI between periods of observation were tested by means of analysis of variance of these models. Following this analysis, post-hoc comparisons between fixed effects were performed using Tukey's procedure. For assessing the validity of the model, the Shapiro-Wilk test was applied for testing normality of the residuals.

For assessing the relationships between supporting force in the more-lame and the less-lame limbs and also between vertical impulse in the two limbs, a regression model with random effects of dog on slope and intercept was used:

$$
y_{i j}=\beta_{0}+b_{0}+\left(\beta_{1}+b_{1}\right) x_{i}+\epsilon_{i j}
$$

with:

$$
b_{0} \sim N\left(0, \sigma_{0}^{2}\right), b_{1} \sim N\left(0, \sigma_{1}^{2}\right), \epsilon_{i j} \sim N\left(0, \sigma^{2}\right)
$$

Here $y_{i j}$ represents the value (PVF or VI) in the less-lame limb and $x_{i j}$ the value in the more-lame limb.

Significance level was set at $P \leq 0.05$ in all tests.

\begin{abstract}
Abbreviations
ADMSCs: Adipose-derived mesenchymal stem cells; MSCs: Mesenchymal stem cells; OA: Osteoarthritis; PVF: Peak vertical force; VI: Vertical impulse; $\mathrm{N}$ : Newton.
\end{abstract}

\section{Competing interests}

The authors declare that they have no competing interests.

\section{Authors' contributions}

$J M V, M B, M R$ and JMC designed the study, drafted the manuscript, and analyzed data; RC and JS revised and edited the manuscript; AS designed and developed the statistical analysis; $\mathrm{MM}$ and BC performed the selection of animals and helped with the revision of the manuscript. JMV and AS were blind researchers. All authors read and approved the final manuscript.

\section{Acknowledgments}

This work was supported by the Fundación García-Cugat and the Veterinary Clinic Hospital of the Universidad de Las Palmas de Gran Canaria. Thomas Oxlee Translations-Editing.

\section{Author details}

'Department of Animal Pathology, Faculty of Veterinary Medicine, Universidad de Las Palmas de Gran Canaria, Trasmontaña S/N, Arucas, 35413 Las Palmas, Spain. ${ }^{2}$ Departamento de Medicina y Cirugía Animal, Universidad CEU Cardenal Herrera, C/Tirant lo Blanc, 7, Alfara del Patriarca, Valencia 46117, Spain. ${ }^{3}$ Fundación García Cugat, Madrazo 43, Barcelona 08006, Spain. ${ }^{4}$ Instituto de Ciencias Biomédicas Universidad CEU Cardenal Herrera, C/del pozo s/n, Alfara del Patriarca, Valencia 46115, Spain. ${ }^{5}$ Garcia Cugat Foundation-UCH Chair, Barcelona, Spain. ${ }^{6}$ Artroscopia GC, Hospital Quirón Barcelona, Plaza Alfonso Comí, 12, Barcelona, Spain.
}

Received: 16 December 2013 Accepted: 19 June 2014 Published: 1 July 2014

\section{References}

1. Bockstahler B, Krautler C, Holler P, Kotschwar A, Vobornik A, Peham C: Pelvic limb kinematics and surface electromyography of the vastus lateralis, biceps femoris, and gluteus medius muscle in dogs with hip osteoarthritis. Vet Surg 2012, 41:54-62.

2. Silvestre AM, Ginja MM, Ferreira AJ, Colaço J: Comparison of estimates of hip dysplasia genetic parameters in Estrela Mountain dog using linear and threshold models. J Anim Sci 2007, 85:1880-1884.

3. Maldonado M, Nam J: The role of changes in extracellular matrix of cartilage in the presence of inflammation on the pathology of osteoarthritis. Biomed Res Int 2013. http://dx.doi.org/10.1155/2013/284873.

4. Oldershaw R: Cell sources for the regeneration of articular cartilage: the past, the horizon and the future. Int Exp Path 2012, 93:389-400.

5. Pigott JH, Ishihara A, Wellman ML, Russell DS, Bertone AL: Inflammatory effects of autologous, genetically modified autologous, allogeneic, and xenogeneic mesenchymal stem cells after intra-articular injection in horses. Vet Comp Orthop Traumatol. In press.

6. Vilar JM, Morales M, Santana A, Spinella G, Rubio M, Cuervo B, Cugat R, Carrillo JM: Controlled, blinded force platform analysis of the effect of intraarticular injection of autologous adipose-derived mesenchymal stem cells associated to PRGF-Endoret in osteoarthritic dogs. BMC Vet Res 2013, 9:131.

7. Takemitsu H, Zhao D, Yamamoto I, Harada Y, Michishita M, Arai T: Comparison of bone marrow and adipose tissue-derived canine mesenchymal stem cells. BMC Vet Res 2012, 8:150

8. Guercio A, Di Marco P, Casella S, Cannella V, Russotto L, Purpari G, Di Bella S, Piccione G: Production of canine mesenchymal stem cells from adipose tissue and their application in dogs with chronic osteoarthritis of the humeroradial joints. Cell Biol Int 2012, 36:189-94.

9. Agung M, Ochi M, Yanada S, Adachi N, Izuta Y, Yamasaki T, Toda K: Mobilization of bone marrow-derived mesenchymal stem cells into theinjured tissues after intraarticular injection and their contribution to tissueregeneration. Knee Surg Sports Traumatol Arthrosc 2006, 14:1307-1314.

10. Harman R, Cowles B, Orava C: A retrospective review of 62 cases of suspensory ligament injury insport horses treated with adipose-derived stem and regenerative cell therapy. In Proceedings of the Veterinary Orthopedic Society. Veterinary Orthopedic Society: Keystone; 2006:212-214.

11. Dahlgren LA: Use of adipose derived stem cells in tendon and ligament injuries. In Proceedings of the American College of Veterinary Surgeons Symposium Equine and Small Animal. Washington: American College of Veterinary Surgeons; 2006:150-151.

12. Nixon A, Dahlgren L, Haupt J, Yeager AE, Ward DL: Effect of adipose-derived nucleated cell fractions on tendon repair in horses with collagenase-induced tendinitis. Am J Vet Res 2008, 69:928-937.

13. Black LL, Gaynor J, Gahring D, Adams C, Aron D, Harman S, Gingerich DA, Harman R: Effect of adipose-derived mesenchymal stem and regenerative cells on lameness in dogs with chronic osteoarthritis of the coxofemoral joints: a randomized, double-blinded, multicenter, controlled trial. Vet Ther 2007, 8:272-84.

14. Black LL, Gaynor J, Adams C, Dhupa S, Sams AE, Taylor R, Harman S, Gingerich DA, Harman R: Effect of intraarticular injection of autologous adipose-derived mesenchymal stem and regenerative cells on clinical signs of chronic osteoarthritis of the elbow joint in dogs. Vet Ther 2008, 9:192-200.

15. Ball SG, Shuttleworth A, Kielty CM: Inhibition of platelet-derived growth factor receptor signaling regulates Oct4 and Nanog expression, cell shape, and mesenchymal stem cell potency. Stem Cells 2012, 30:548-60.

16. Rodríguez FJ, Valdés T, Carrillo JM, Rubio M, Monleon M, García DM, García M, Cugat R, Moreno V: Platelet-rich plasma favors proliferation of canine adipose-derived mesenchymal stem cells in methacrylate-endcapped caprolactone porous scaffold niches. J Funct Biomater 2012, 3:556-568.

17. Bennett RL, DeCamp CE, Flo GL, Hauptman JG, Stajich M: Kinematic gait analysis in dogs with hip dysplasia. Am J Vet Res 1996, 7:966-971.

18. Poy NS, DeCamp CE, Bennett RL, Hauptman JG: Additional kinematic variables to describe differences in the trot between clinically normal dogs and dogs with hip dysplasia. Am J Vet Res 2000, 8:974-978.

19. Gordon WJ, Conzemius MG, Riedesel E, Besancon MF, Evans R, Wilke V, Ritter MJ: The relationship betweenlimb function and radiographic osteoarthrosis in dogs with stifle osteoarthrosis. Vet Surg 2003, 32:451-454.

20. Voss K, Imhof J, Kaestner S, Montavon PM: Force plate gaitanalysis at the walk and trot in dogs with low-grade hindlimb lameness. Vet Comp Orthop Traumatol 2007, 20:299-304. 
21. Evans R, Gordon W, Conzemius M: Effect of velocity on ground reaction forces in dogs with lameness attributable to tearing of the cranial cruciate ligament. Am J Vet Res 2003, 64:1479-1481.

22. Vilar JM, Morales M, Santana A, Batista M, Miró F, Spinella G: Long-term valuation of oral mavacoxib in Osteoarthrosic dogs using force platform analysis. Pak Vet J 2013, 33:229-233.

23. Moreau M, Lussier B, Doucet M, Vincent G, Martel-Pelletier J, Pelletier JP: Efficacy of licofelone in dogs with clinical osteoarthritis. Vet Rec 2007, 160:584-588.

24. Bennett RL, DeCamp CE, Flo GL, Hauptman JG, Stajich M: Kinematic gait analysis in dogs with hip dysplasia. Am J Vet Res 1996, 57:966-71.

25. DeCamp CE, Riggs CM, Olivier NB, Hauptman JG, Hottinger HA, Soutas-Little RW: Kinematic evaluation of gait in dogs with cranial cruciate ligament rupture. Am J Vet Res 1996, 57:120-126.

26. Budsberg SC, Johnston SA, Schwarz PD, DeCamp CE, Claxton R: Efficacy of etodolac for the treatment of osteoarthritis of the hip joints in dogs. J Am Vet Med Assoc 1999, 214:206-210.

27. Bigham-Sadegh A, Mirshokraei P, Karimi I, Oryan A, Apaniz A, Shafiei-Sarvestani Z: Effects of adipose tissue stem cell concurrent with greater omentum on experimental long-bone healing in dog. Connect Tissue Res 2012, 53:334-342.

28. Haghighat A, Akhavan A, Hashemi-Beni B, Deihimi P, Yadegari A, Heidari F: Adipose derived stem cells for treatment of mandibular bone defects: an autologous study in dogs. Dent Res J (Isfahan) 2011, 8(Suppl1):51-57.

29. Kang BJ, Ryu HH, Park SS, Koyama Y, Kikuchi M, Woo HM, Kim WH, Kweon OK: Comparing the osteogenic potential of canine mesenchymal cells derived from adipose tissues, bone marrow, umbilical cord blood, and wharton's jelly for treating bone defects. J Vet Sci 2012, 13:299-310.

30. Oh HJ, Park EJ, Lee SY, Soh JW, Kong IS, Choi SW, Ra JC, Kang SK, Lee BC: Comparison of cell proliferation and epigenetic modification of gene expression patterns in canine foetal fibroblasts and adipose tissue-derived mesenchymal stem cells. Cell Prolif 2012, 45:438-444.

31. Murphy JM, Fink DJ, Hunziker EB, Barry FP: Stem cell therapy in a caprine model of osteoarthritis. Arthritis Rheum 2003, 48:3464-3474.

32. Vogel PL: Surgeon's use of adipose stem cell therapy [abstract]. Vet Comp Orthop Traumatol 2012, 3:10.

33. Koh YG, Jo SB, Kwon OR, Suh DS, Lee SW, Park SH, Choi YJ: Mesenchymal stem cell injections improve symptoms of knee osteoarthritis. Arthroscopy 2013, 29:748-755.

34. Pinheiro J, Bates D: Fitting linear mixed-effects models. In Mixed-effects models in S and S-PLUS. 1st edition. Edited by Chambers J. New York: Springer-Verlag; 2000:133-197.

35. Milliken GA, Johnson DE: Analysis of mixed models/case studies of a mixed model. In Analysis of Messy Data, Volume 1. 2nd edition. Florida: Chapman and Hall; 2009:385-417.

36. Certificate for hip and elbow dysplasia. http://www.fci.be/uploaded_files/ 77-2001.pdf.

37. Piermattei D, Flo G, DeCamp C: Orthopedic examination and diagnostic tools. In Brinker, Piermattei and Flo's Handbook of Small Orthopedics and Fracture Repair. 4th edition. Edited by Fathman L. Missoury: Saunders; 2006:3-24.

38. R Development Core Team: R: A language and environment for statistical computing. http://www.R-project.org/.

\section{doi:10.1186/1746-6148-10-143}

Cite this article as: Vilar et al:: Assessment of the effect of intraarticular injection of autologous adipose-derived mesenchymal stem cells in osteoarthritic dogs using a double blinded force platform analysis. BMC Veterinary Research 2014 10:143.

\section{Submit your next manuscript to BioMed Central and take full advantage of:}

- Convenient online submission

- Thorough peer review

- No space constraints or color figure charges

- Immediate publication on acceptance

- Inclusion in PubMed, CAS, Scopus and Google Scholar

- Research which is freely available for redistribution 